\title{
IV.
}

\section{Vorläufige Notiz über die Verbindungen des Phosphors mit Aethyl.}

\author{
Von.
}

\section{Dr. Ferdinand Berlé \\ aus Wiesbaden.}

Phosphornatrium lässt sich in grösserer Menge nicht rein erhalten. Lässt man Phosphor und Natrium direct auf einander einwirken, so ist die dabei frei werdende Hitze so gross, dass selbst die besten Berliner Porcellantiegel springen. Nur geringe Quantitäten lassen sich auf diese Weise darstellen. Versuche, durch die Reaction von Phosphordämpfen auf weiss glühenden verkohlten Weinstein, oder von Kohle auf phosphorsaures Natron die Legirung zu erhalten, ergaben ebenfalls keine Resultate. Die einzige Methode, Phosphornatrium darzustellen, besteht darin, dass Natrium unter Steinöl geschmolzen und kleine Stückchen Phosphor nach und nach ihm zugesetzt werden. Auch hier war die frei werdende Wärme keine unbedeutende, und steigerte sich zuweilen bis zur Entzündung des Steinöls.

Das hierdurch gebildete Phosphornatrium war eine schwarze, körnig pulverige Masse, welche sich jedoch von dem stets anhängenden Steinöle nicht vollständig befreien liess. Die letzten Theilchen hafteten sogar dann noch an, wenn die Temperatur bis zur Zersetzung des Phosphornatriums gesteigert worden war.

Dieses rückständige Steinöl verhindert wahrscheinlich auch eine lebhaftere Einwirkung von Jodäthyl auf die auf diese Weise dargestellte Legirung. Erst bei hoher Temperatur fand nämlich eine solche Statt. Herr Prof. Löwig verfuhr hierbei nach derselben Methode, die er bei der Darstellung des Stibäthyls anwandte, nur musste während der ganzen Operation Kohlensäure durch das Kölbchen, welches das Gemenge von Phosphornatrium und Jodäthyl enthielt, geleitet werden. Das Phosphornatrium wurde 
nicht mit Sand vermischt. Nachdem das überschüssige Jodäthyl abdestillirt war, zeigte sich, namentlich bei einem raschen Strome von Kohlensäure, in der Vorlage ein weisser Rauch, der später von einer gelben, an der Luft stark rauchenden Flüssigkeit begleitet war. Diese Flüssigkeit war wahrscheinlich Phosphortriäthyl: $\mathrm{PAe}_{3}$. Wurde sie nämlich mit Jodäthyl zusammen erwärmt, so erstarrte sie zu einer gelblich-weissen krystallinischen Masse, deren Analyse eine der Verbindung $\left(\mathrm{PAe}_{4}\right) \mathrm{J}$ sehr nahe kommende Zusammensetzung zeigte. Bei zwei Jodbestimmungen erhielt ich nämlich statt der berechneten 46,3 p. C. Jod das eine Mal 45,5, das andere Mal 47,8 p. C. Jod. Genauere Resultate konnte ich deswegen nicht erhalten, weil die Verbindung nicht ganz rein war, sondern ihr stets noch durch den Geruch wahrzunehmende Spuren von Steinöl anhingen, von denen sie sich nicht befreien liess. Nach mehrmaligem Umkrystallisiren stellte sie eine an der Luft leicht zerfliessliche Masse von eigenthümlichem, bittern Geruch und Geschmacke dar, war in Wasser und Weingeist leicht, in Aether schwer löslich. In ihren übrigen Eigenschaften kam sie dem $\mathrm{J}\left(\mathrm{SbAe}_{4}\right)$ sehr nahe.

Da man auf diese Weise kein reines Phosphoräthyl erhalten konnte, so versuchte ich durch Einschmelzen von Jodäthyl, Phosphor und Natrium in eine starke Glasröhre, die alsdann der mehrstündigen Einwirkung des Wasserbades ausgesetzt wurde, neue Resultate zu erzielen. Nach sechs Stunden war die Flüssigkeit, von etwas überschüssigem Jodäthyl abgesehen, vollständig erstarrt. Beim Oeffnen der Röhre entwich ein brennbares Gas, wahrscheinlich Aethyl. Die Masse wurde mit wenig Wasser ausgezogen, und um das gelöste Jodnatrium zu entfernen, mit Aether und Alkohol versetzt. Die vom untenstehenden Wasser getrennte äther-alkoholische Lösung gab beim Verdunsten undeutliche Krystalle, welche aber beim Umkrystallisiren aus Wasser in beinahe einen halben Zoll langen Nadeln anschossen. Eine Jodbestimmung dieser Nadeln ergab 67,77 p. C. Jod; die Verbindung $\left(\mathrm{PAe}_{3}\right) \mathrm{Jd}+\mathrm{HJd}$ verlangt 67,2 p. C. Jod. In grösserem Maasstabe lässt sich diese Operation jedoch nicht ausführen, da bei einem derartigen 
Versuche, bei welchem ich $1 / 4$ Pfund Jodäthyl anwandte, eine sehr bedeutende Explosion statt fand. Phosphor löst sich in der Wärme in grosser Menge in Jodäthyl, aber Phosphoräthyl wird nicht gebildet, auch wenn man mehre Tage lang die Lösung einer Temperatur yon $100^{\circ}$ aussetzt.

Ich glaube hieraus den vorläufigen Schluss ziehen zu dürfen, dass der erste dieser neuen Körper $\mathrm{J}\left(\mathrm{PAe}_{4}\right) J_{0 d-}$ phosphoräthylium, der zweite $\mathrm{J}_{2}\left(\mathrm{PAe}_{3}\right)$ Jodphosphortriathyl ist.

\section{V. \\ Ueber eine neue Classe organischer Radikale.}

Von

Ad. Wurtz.

(Compt. rond. t. $\mathrm{KL},($ (No. 25.) 1855. p. 1285.)

Die in den Alkoholen und Aethern angenommenen Radikale sind bekanntlich von Kolbe und Frankland isolirt worden.

Sie haben durch Elektrolyse der flüchtigen Fettsäuren $\mathrm{C}_{\mathrm{n}} \mathrm{H}_{12} \mathrm{O}_{4}$ und durch Zersetzung der Jodwasserstoffäther mittelst Zink die Kohlenwasserstoffe Methyl, Aethyl, Butyl und Amyl dargestellt und dafür die resp. Formeln $\mathrm{C}_{2} \mathrm{H}_{3}$, $\mathrm{C}_{4} \mathrm{H}_{5}, \mathrm{C}_{8} \mathrm{H}_{3}$ und $\mathrm{C}_{10} \mathrm{H}_{11}$ angenommen. Später kam zu dieser Reihe noch ein neuer Kohlenwasserstoff, das Capryl, $\mathrm{C}_{\mathbf{1 2}} \mathrm{H}_{\mathbf{1 3}}$. Wie man sieht, haben Kolbe und Frankland für die Alkoholradikale im freien Zustande die Atomgewichte und chemischen Formeln beibehalten, welche diese in ihren Verbindungen haben. So wie sie in den Alkoholen existiren, würden sie auch nach der Isolotion bleiben und in diesem Zustande würde ihr Aequival. 2 Vol. Dampf entsprechen.

Diese Ansicht ist nicht von allen Chemikern adoptirt worden. Laurent und Gerhardt haben bekanntlich zuerst vergeschlagen, die Formeln der Àlkoholradikale zu 